\title{
Biotic Stress Induced Biochemical and Isozyme Variations in Ginger and Tomato by Ralstonia solanacearum
}

\author{
Sasidharan Sreedevi ${ }^{1,2}$, Kulangara Nanu Remani $^{2}$, Sailas Benjamin ${ }^{{ }^{*}}$ \\ ${ }^{1}$ Enzyme Technology Laboratory, Biotechnology Division, Department of Botany, University of Calicut, Malappuram, India; ${ }^{2}$ Envi- \\ ronmental Studies Division, Centre for Water Resources Development and Management (CWRDM), Calicut, India. \\ Email: ${ }^{*}$ sailasben@yahoo.co.in, ${ }^{*}$ benjamin@uoc.ac.in
}

Received May $13^{\text {th }}, 2013$; revised June $14^{\text {th }}, 2013$; accepted July $15^{\text {th }}, 2013$

Copyright (C) 2013 Sasidharan Sreedevi et al. This is an open access article distributed under the Creative Commons Attribution License, which permits unrestricted use, distribution, and reproduction in any medium, provided the original work is properly cited.

\begin{abstract}
This unique study evaluates the effects of Ralstonia solanacearum (Rs) induced biotic stress in two cultivars, Zingiber officinale (ginger) and Lycopersicon esculentum (tomato). They were grown in pots and hydroponic systems with controls; to induce biotic stress, about $8 \times 10^{4}$ colony forming units of Rs suspension was injected into the healthy test plants. Upon induction of Rs stress, highly significant $(p<0.01)$ biochemical changes $(\%)$ were noticed in respect to controls: carbohydrate content was generally high in both plants; while they showed decreased starch and protein contents; phenolics showed a swing of decrease or increase between pot and hydroponic systems; and all plants in general showed higher (3 - 6 fold) proline content upon induction of biotic stress. Regarding oxidative stress isozymes (OSE), superoxide dismutase (EC 1.15.1.1) isozymes were normally 3, but treated hydroponics had 4 with comparable relative mobility values; peroxidase (EC 1.11.1.7) isozymes were generally 2, except for treated hydroponic tomato. Briefly, Rs induced biotic stress caused wilt symptoms in ginger, but did not affect tomato though its biochemical and OSE patterns especially in those grown as hydroponics were elicited to significantly higher levels.
\end{abstract}

Keywords: Biotic Stress; Hydroponics; Stress Enzymes; R. solanacearum; L. esculentum; Z. officinale

\section{Introduction}

Ralstonia solanacearum (Rs) is a devastating plant pathogen with a global distribution and an unusually wide host range, which in the absence of host plants can also be free-living as a saprophyte in water or in the soil [1]. This soil-borne plant Gram negative, aerobic, nonsporulating, motile and pathogenic bacterium colonizes the xylem vessels of infected plants thereby causing lethal wilt diseases in many cultivars like tomato, potato, banana, egg plant, tobacco, ginger, etc. and also wild plants throughout the world - especially in tropical, subtropical and warm temperate climates $[2,3]$. The mucus secreted by the Rs plugs the xylem vessels, which causes impedance to the vascular activity and this clearly indicates the direct mechanical involvement of exopolysaccharide (EPS) in pathogenicity with wilting symptoms; upon wound or cut, Rs will ooze out as a streaming thread along with its mucus secretion [4]. Their very high cell density in xylem, the various by-products of plant cell wall degradation like tyloses and gums would also con-

*Corresponding author. tribute to wilting [3]. Bacterial wilt of tomato caused by Rs is one of the most devastating diseases of tomato, and the incidence increases in tomato fields by either the intimate contact between roots of adjacent tomato plants or the movement of the pathogen through surface irrigation [5]. Similarly, ginger is highly susceptible to many strains of Rs, and susceptible plants wilted within three weeks upon stem inoculation [6].

During many environmental stressors like extreme temperature, high salinity, mineral deficiencies and pathogenic attack, numerous activated oxygen species such as superoxide, $\mathrm{H}_{2} \mathrm{O}_{2}$ and hydroxyl radical would be produced in plants as marker molecules [7]. Plants possess a number of antioxidants that protect them from these harmful and highly reactive oxygen species (ROS). However, in recent years, it has become apparent that plants actively produce ROS as signaling molecules to control processes such as programmed cell death, abiotic stress responses, pathogen defense and systemic signalling [8]. The oxidative stress enzyme (OSE) markers like superoxide dismutase (SOD; EC 1.15.1.1), a wide variety 
of peroxidases (POX; EC 1.11.1.11), and catalase (CAT; EC 1.11.1.6) have been reported to provide sufficient resistance against oxidative damage caused by these ROS [7]. Different enzyme assay methods and relative mobility $(\mathrm{Rm})$ of their protein bands on gels after electrophoresis are employed to determine the generation of stress tolerant proteins or isoenzymes of the aforesaid OSE in test plants [8]. For the study of stress physiology in plants, both pot [9] and hydroponic [10] systems have widely been used as a cultivation strategy.

Even though plants were widely studied for various abiotic stressors, the effect of biotic stress (especially pathogenic) is comparatively less addressed and documented. Thus, we designed this study to evaluate the changes in the biochemical profiles and OSE isozyme patterns - after infecting with Rs - on two popular cultivars (tomato and ginger), which are known to be susceptible for Rs attack. Accordingly, the specific objectives are to: 1) frame a suitable experimental design, 2) isolate and characterize Rs from infected ginger, 3) cultivate two cultivars (ginger and tomato) in pot and hydroponic systems with sufficient controls, 4) transfer Rs isolate artificially in to these plants, 5) analyze the plants for biochemical changes, 6) analyze the changes of SOD, POX and CAT isoymes in these plant, and to 7) re-confirm that the isolate is Rs.

\section{Materials and Methods}

\subsection{Collection of the Pathogen, $R$. solanacearum (Rs)}

Rs infected rhizomes (rotten and fluffy) of Zingiber officinale Roscoe (ginger) with characteristic wilt symptoms were collected from the ginger farm maintained by the Indian Institute of Spices Research (IISR), at Peruvannamuzhi, Kozhikode, India $\left(11^{\circ} 35^{\prime} 0^{\prime \prime} \mathrm{N} ; 75^{\circ} 49^{\prime} 0^{\prime \prime} \mathrm{E}\right)$ during the rainy season, i.e., South-West (S-W) monsoon (June-July), the season in which severe ginger wilt occurs in Kerala. It was transported to the lab in a sterile container.

\subsection{Stem Streaming Test}

The stem-streaming test was used as a simple presumptive test for identifying Rs [11]. Briefly, rhizome from infected ginger was cut into thin sections with a sterile blade and $1 \mathrm{~g}$ was transferred into a test tube containing 5 $\mathrm{ml}$ sterile distilled water $\left(\mathrm{ddH}_{2} \mathrm{O}\right)$ for isolating the Rs culture for this study. In order to obtain spontaneous streaming of slimy bacterial threads (bacteria with EPS) from the cut vascular bundles, the rhizome slices were immersed into $\mathrm{ddH}_{2} \mathrm{O}$ in the test tube for $5-10 \mathrm{~min}$. This bacterial solution was properly diluted for spread or streak plating.

\subsection{Isolation of Pure Cultures}

The bacterial solution obtained as above was serially diluted $\left(10^{-3}\right)$ for spread plate on to the Kelman's selective tetrazolium chloride-agar (TZC) medium.TZC consisted of (g/l) peptone, 10; glucose, 5; casamino acid, 1; yeast extract, 1; and agar $18(\mathrm{pH} \mathrm{7.2)}$, autoclaved (15 $\psi$, $121^{\circ} \mathrm{C}, 20 \mathrm{~min}$ ), cooled the medium to $55^{\circ} \mathrm{C}$ and $5 \mathrm{ml}$ (for molten medium) of $1 \%$ filter-sterilized 2,3,5-triphenyl tetrazolium chloride added [12]. Casein-peptone-glucose (CPG) agar medium (pH 7.2) was also used for culture. The variations in colour and morphology of the bacterial colonies in both TZC and CPG media were carefully noted.

\subsection{Biochemical Characterization of $\boldsymbol{R}$. solanacearum}

The routine microbiological and biochemical characterizations of the isolate (as above) was accomplished, which included: Gram staining, hanging-drop motility, indolemethyl-red. Voges-Proskauer.citrate (IMViC), triple-sugar-iron agar (TSI), catalase, oxidase and arginine dehydrogenase tests.

\subsection{Collection of Test Plants}

Tomato (Lycopersicon esculentum Miller) and ginger ( $Z$. officinale Roscoe) were used in this study. The tomato seeds of disease-free healthy plants were collected in March, prior to the S-W monsoon from a farm near Kun-

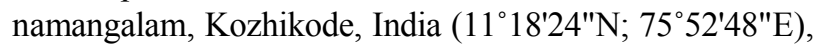
the seeds were kept under dry condition before planting. Rhizomes of ginger which was healthy and disease-free were selected from a farm under Indian Institute of Spices Research (IISR) at Peruvannamuzhi, Kozhikode $\left(11^{\circ} 35^{\prime} 0 " \mathrm{~N}\right.$; $\left.75^{\circ} 49^{\prime} 0 " \mathrm{E}\right)$ in March, prior to the S-W monsoon. The selected rhizomes were washed in $\mathrm{ddH}_{2} \mathrm{O}$ and air-dried in shade and stored in cool-dry place in a sterile environment.

\subsection{Method of Cultivation}

Test plants included tomato and ginger which were planted in two environments: in well nourished pots and saplings in hydroponic condition. Each group (in pot and as hydroponics) of plants was grown in sufficient numbers (5 each) for control and treatment (injected with Rs isolate).

\subsubsection{Cultivation in Pot}

All test plant was planted in pots containing garden soil, sand and farmyard manure (1:1:1). Initially, plants were acclimatized in a green house with a night time minima of $20^{\circ} \mathrm{C}-25^{\circ} \mathrm{C}$ and a day time maxima of $29^{\circ} \mathrm{C}-34^{\circ} \mathrm{C}$. After one month in green house, plants were transferred 
to open air. Vigor of the test plants was maintained by frequent watering. The treated plants were kept away from the control to prevent spreading of Rs infection.

\subsubsection{Cultivation in Hydroponic System}

One month old healthy saplings (in green house), were transferred to hydroponic system. Shive and Robbins medium [13] was used for the cultivation of plants in hydroponic system. It contained (g/L): $\mathrm{NaNO}_{3}, 3.4$; $\mathrm{CaCl}_{2}, 1.665 ; \mathrm{KH}_{2} \mathrm{PO}_{4}, 2.14, \mathrm{MgSO}_{4} 5.14$ and trace elements like $\mathrm{FeSO}_{4} \cdot 7 \mathrm{H}_{2} \mathrm{O}, 0.00275 ; \mathrm{H}_{3} \mathrm{BO}_{3}, 0.00285$; $\mathrm{MnSO}_{4}, 0.00285$ and $\mathrm{ZnSO}_{4}, 0.00285$ (pH 6.5). The hydroponic cultures were maintained in glass bottles and were kept $\left(\sim 28^{\circ} \mathrm{C}\right)$ in sterile environment in such a way to receive ample sun light. The cultures were aerated intermittently with an air bubbler. The nutrient solution was replaced by freshly prepared solution in every 1 week.

\subsection{Transfer of Infection to the Test Plants}

The pathogen, $R$. solanacearum isolate (as obtained above) was injected into the lower part of the stem of all the test plants (both pot and hydroponics). Regarding hydroponics, injection was made after acclimatization (1 week). Prior to inoculation, plants (in pot) were not watered for one day. Plants were inoculated with a syringe fitted with a $23 \mathrm{G}$ hypodermic needle, $0.5 \mathrm{~mL}$ of Rs ooze out in water from the soft rotten rhizome containing $\sim 8 \times$ $10^{4}$ (in $0.5 \mathrm{~mL}$ injected) colony forming units, (CFU) . The treated plants were kept strictly apart from the control plants to avoid cross infection.

\subsection{Biochemical Analyses}

Six biochemical tests were performed on the test and control plants, they were: estimation of total (\%) carbohydrate, starch, reducing sugar, protein, phenol and proline. The total carbohydrate and starch contents in the sample were analyzed by Anthrone method [14]. The total protein in the sample was analyzed by Lowry's method [15]. The phenol content in the sample was checked using Folin-Ciocalteau reagent [14]. The total proline content in the sample was estimated at $520 \mathrm{~nm}$ using acidic ninhydrin to form the chromophore (red colour) [14].

\subsection{Isozyme Analyses}

Employing native polyacrylamide gel electrophoresis (PAGE) [16], the oxidative stress enzymes (i.e., isozyme) such as superoxide dismutase (SOD), peroxidase (POX) and catalase (CAT) were analyzed in this study. $2 \mathrm{~g}$ of leaf was weighed out and homogenized with liquid nitrogen (Iwatani-NL-50, Japan) at $-196^{\circ} \mathrm{C}$ and suspended in $0.05 \mathrm{M}$ Tris buffer ( $\mathrm{pH} 7.2$ ), which was kept for $2 \mathrm{~h}$ at $4^{\circ} \mathrm{C}$. This was filtered using cheese cloth and the extract was centrifuged at $9400 \times \mathrm{g}, 4^{\circ} \mathrm{C}$ for $20 \mathrm{~min}$ and the supernatant was used for analyses. PAGE gel was prepared with 5\% stacking gel and $10 \%$ separating gel, run at $4{ }^{\circ} \mathrm{C}$ for $3 \mathrm{~h}$ at $40 \mathrm{~mA}$. With the completion of the electrophoresis, the gel was carefully removed and soaked in suitable staining solutions. Method of Ravindranath and Fridovich [17] was used for SOD staining in which bands appeared as clear areas on the gel. Benzidine staining method was used for detection of POX isozymes [14] in which appearance of bright blue bands indicates its presence. For the presence of catalase, the gel was washed with $\mathrm{ddH}_{2} \mathrm{O}$ and $50 \mathrm{~mL}$ solution containing potassium ferric cyanide $(250 \mathrm{mg})$ and $\mathrm{FeCl}_{2}(250 \mathrm{mg})$ was added to visualize yellowish bands [14].

\subsection{Relative Mobility Calculation}

Relative mobility (Rm) of the isozyme bands was calculated based on their relative migration on the gel. The images of gel were taken on a gel documentation system (Bio-Rad Gel Doc XR) and then the images were processed using Total Lab Technology software (TL 100 Single dongle UK, by non-linear dynamics).

\subsection{Confirmation of Rs Infection}

The infected plants were checked daily (up to four weeks) for evaluation of pathogenicity and severity of infection. Disease severity was assessed at weekly intervals to see whether a single leaf is wilted, yellowing started, curling occurred and until the susceptible plant was dead. When the plants showed the wilt symptoms for confirmation of the pathogen responsible, the stem from one of the experimental plants (ginger) was cut above the soil layer level and immersed the cut end into the sterile water. A milky bacterial suspension streamed out, which was then spread on to the TZC agar plate. The appearance of characteristic colonies was noted to confirm the wilting was due to infection by Rs isolate.

\subsection{Statistics}

Statistical Package for Social Sciences (SPSS) was used to prepare the graphs and significance level at 0.05 and 0.01 by Student's t-test. Two-tailed test of significance was done for all the samples. Adobe Photoshop CS5 was used to set the figures.

\section{Results}

The prime objective of this study was to examine the biochemical changes and expression profiles of the oxidative stress enzymes (OSE) due to the biotic stress induced by infecting the test plants with $R$. solanacearum 
(Rs). Two cultivars viz., (L. esculentum and Z. officinale) known for susceptible to the attack of Rs were used in this study. In the experimental design, all plants (in sufficient number) were grown in two sets, i.e., in pot and hydroponic systems (Figure 1).

\subsection{Bacterial Culture Used}

Rs culture used in this study for inducing biotic stress was isolated fresh form the rhizome of severely infected ginger plants. It showed the typical characteristics of Rs (Figure 2).

\subsection{Streak Plate on TZC or CPG Agar}

Upon incubation for $48 \mathrm{~h}\left(28^{\circ} \mathrm{C}\right)$ on TZC-agar, Rs produced characteristic reddish-pink (of formazan pigment from TZC), opaque, convex, round and smooth colonies sized 2 - $3 \mathrm{~mm}$ with increasing pink colour intensity towards the centre of the colony (Figures 2(A) and (B)). Centrally formed discrete colony on the plate was selected for re-streaking on CPG-agar plate for getting fluidal white, dense opaque, convex, round and colony, which appeared after $48 \mathrm{~h}$ incubation $\left(28^{\circ} \mathrm{C}\right)$ (Figure 2(C)).

\subsection{Biochemical Characterization of Rs}

Six physico-biochemical tests were performed to check the characteristics of Rs, they were: hanging drop motility test, Gram staining, IMViC, TSI, catalase, oxidase and arginine (Table 1). Of them, it was positive for motility test, Gram staining, catalase, oxidase, arginine and citrate untilization, but TSI was intermediate (the butt

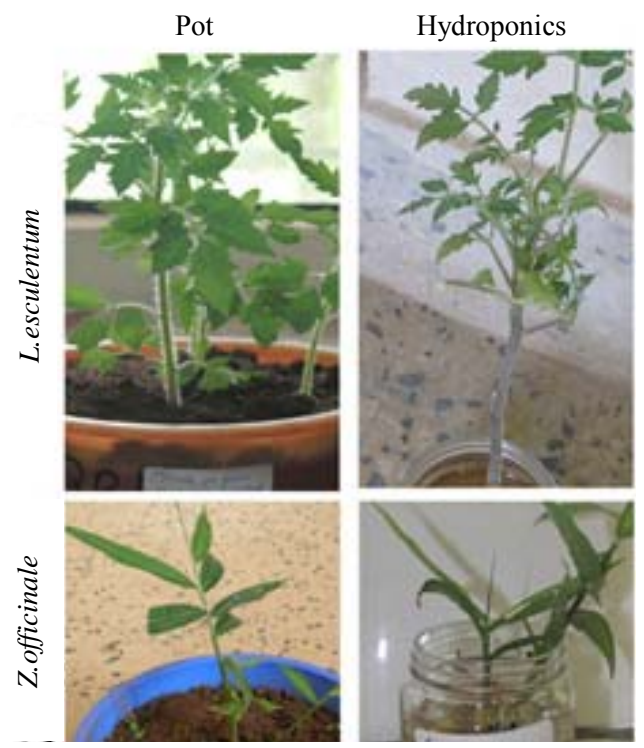

Figure 1. Experimental design of plants: Two cultivars (tomato and ginger) were grown in pot and hydroponic systems in sufficient number with controls.

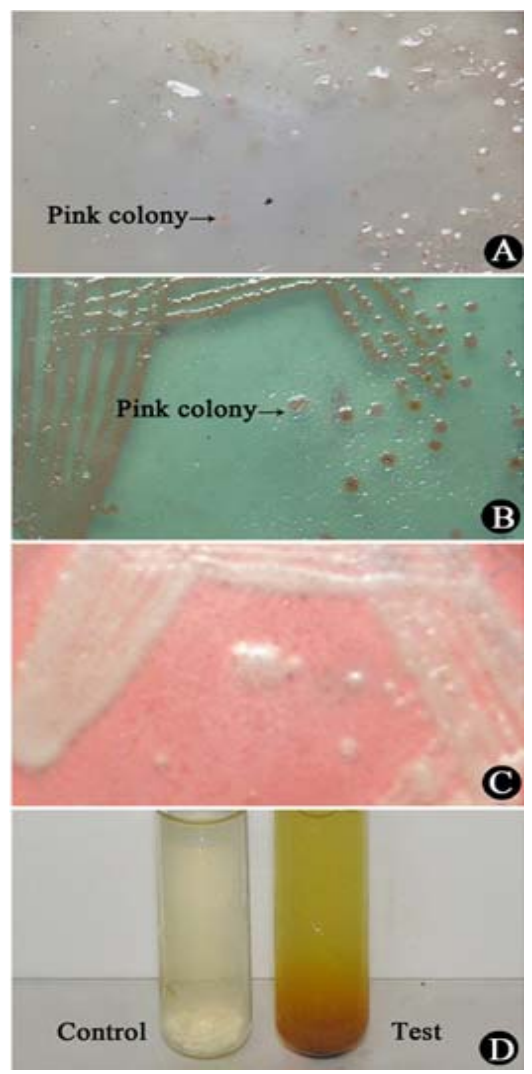

Figure 2. (A)-(D) Isolation and characterization of $R$. solanacearum from infected rhizomes of ginger: A) the streaming thread collected in $\mathrm{ddH}_{2} \mathrm{O}$ spread on TZC medium, characteristic pink colonies are seen after $48 \mathrm{~h}$ incubation at $28^{\circ} \mathrm{C}$; B) single colonies from " $A$ " above streaked in TZC plate, prominent colonies seen after $48 \mathrm{~h}$ at $28^{\circ} \mathrm{C}$; $\mathrm{C}$ ) the colony from " $\mathrm{B}$ " above streaked on CPG agar for getting fluidal and white colonies after $48 \mathrm{~h}$ at $28^{\circ} \mathrm{C}$; D) positive test for arginine dehydrogenase, the confirmation test for Rs.

Table 1. Biochemical characteristics of Ralstonia solanacearum isolate from wilted ginger.

\begin{tabular}{cc}
\hline Test & Result \\
\hline Motility & + \\
Gram stain & - \\
IMViC &,,,---+ \\
TSI & + \\
Catalase & + \\
Oxidase & + \\
Arginine & + \\
\hline
\end{tabular}

was negative and slant positive). The arginine test, which is specific for Rs was positive (Figure 2(D)). All the aforesaid results categorically proved that the isolate from ginger was an Rs strain. 


\subsection{Biochemical Profiles}

In order to examine the biochemical behaviours due to Rs infection, six biochemical components of the five plants under examination were analyzed as subdivided below (Figures 3(a)-(f)).
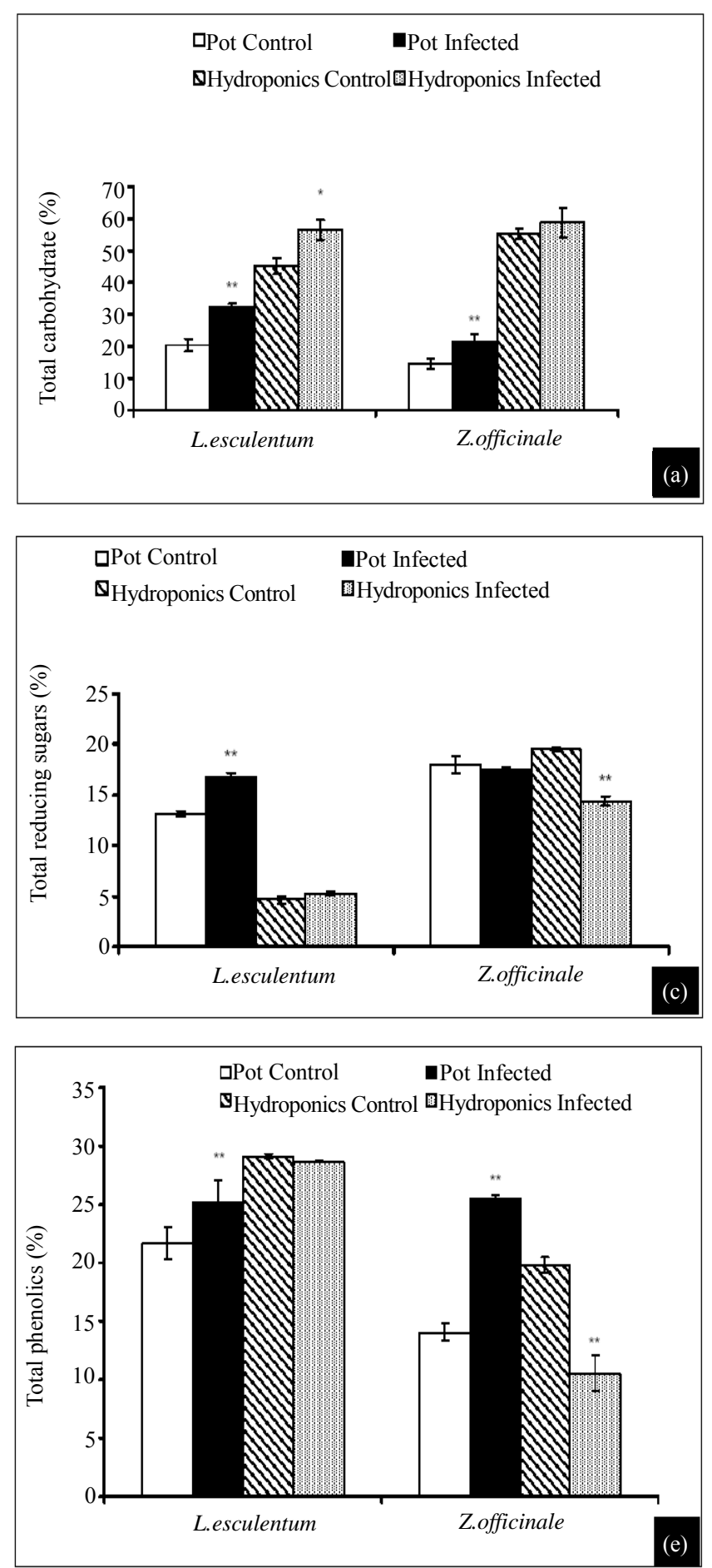

\subsubsection{Estimation of Total Carbohydrate}

Profiles of total carbohydrate content in plants grown in pots and as hydroponics (both Rs infected) showed variations against their respective controls (Figure $3(\mathbf{a})$ ). Tomato showed $36 \%$ increase (pot), while its hydroponics showed 25\% increase, however, total carbohydrate
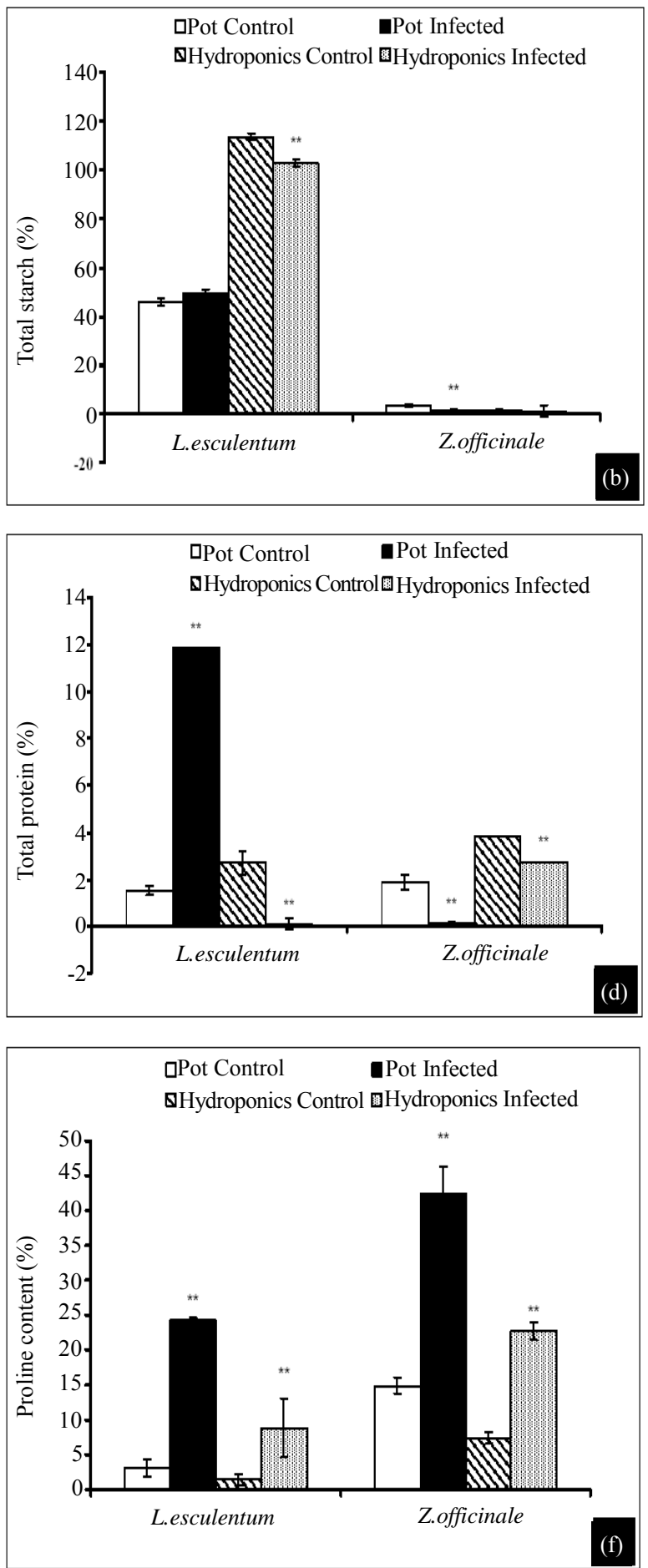

Figure 3. (a)-(f) Biochemical characterization of test plants: (a) Total carbohydrate, (b) total starch, (c) total reducing sugars, (d) total protein, (e) potal phenolics, and (f) proline content. ${ }^{*}$ Indicates significance at $p<0.05$ and ${ }^{* *}$ at $p<0.01$. 
content in ginger was $33 \%$ more (pot) with no significant difference in its hydroponics. Results show that carbohydrate content in all infected plants in pot was high in the range $24 \%-36 \%$, while corresponding infected hydroponic plants showed no significant difference or an increase of around $20 \%$.

\subsubsection{Estimation of Total Starch}

Profiles of total starch content in plants grown in pots and as hydroponics (both Rs infected) showed variations against their respective controls (Figure 3(b)). Tomato (pot), showed an insignificant increase while its hydro ponics showed $10 \%$ decrease, however, total starch content in ginger was very low in control $(3.25 \%)$, which further decreased to $1.28 \%$ (infected, pot) with no significant difference in its hydroponics. Briefly, infected tomato and ginger (both in pots and as hydroponics) showed decreased starch content than their controls.

\subsubsection{Estimation of Total Reducing Sugar}

Profiles of total reducing sugar in plants grown in pots and as hydroponics (both Rs infected) showed variations against their respective controls (Figure 3(c)). Tomato showed insignificant increase in both (infected) pot and hydroponic systems, and more or less similar effect noticed in gingers too.

\subsubsection{Estimation of Total Protein}

Profiles of total protein in plants grown in pots and as hydroponics (both Rs infected) showed variations against their respective controls (Figure 3(d)). Tomato showed $87 \%$ (7.7 fold) increase over its control (pot), while its hydroponics showed $96 \%$ decrease, however, total protein content in ginger grown in pot showed $93 \%$ and $29 \%$ decrease, respectively in pot and hydroponics. Interestingly, the protein content in infected tomato and ginger was generally low.

\subsubsection{Total Phenolic Content}

Profiles of total phenolics in plants grown in pots and as hydroponics (both Rs infected) showed variations against their respective controls (Figure 3(e)). Tomato showed $14 \%$ increase over its control (pot), while its hydroponics showed no significant increase increase, however, total phenolic content in ginger grown in pot showed $46 \%$ increase, while its hydroponics showed 53\% lower phenolics. The results show that infected plants (both in pot and hydroponic systems) did not show a consistent pattern of phenolic contents, which showed a swing of decrease or increase between pot and hydroponic systems.

\subsubsection{Total Proline Content}

Profiles of proline in plants grown in pots and hydroponics (both Rs infected) showed variations against their respective controls (Figure 3(f)). Tomato showed 8 fold increase over its control (pot) while its hydroponics showed 6 fold increase, however proline content in infected ginger was 3 fold higher both in pot and hydroponic systems. All infected plants in general showed elevated proline content, however, its increase was 3 to 8 fold higher in tomato and ginger.

\subsection{Isozyme Analysis}

Three representative enzymes of oxidative stress, viz., SOD and POX were analyzed based on their physical appearance on the PAGE upon specific staining and relative Rm values (Figures $\mathbf{4}$ and 5, Tables $\mathbf{2}$ and 3, respectively).

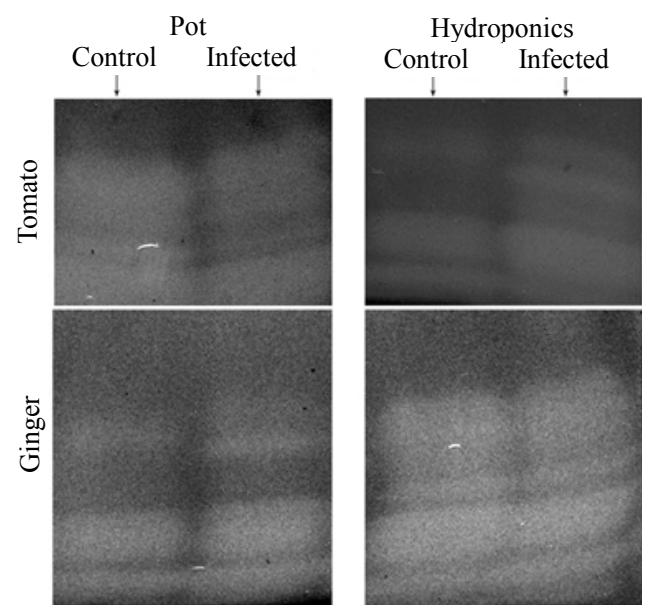

Figure 4. Isozyme profiles of SOD of plants in pot and hydroponic systems with respective controls: left row is of the two cultivars (tomato and ginger) grown in pots and right row is of such plants in hydroponic state.

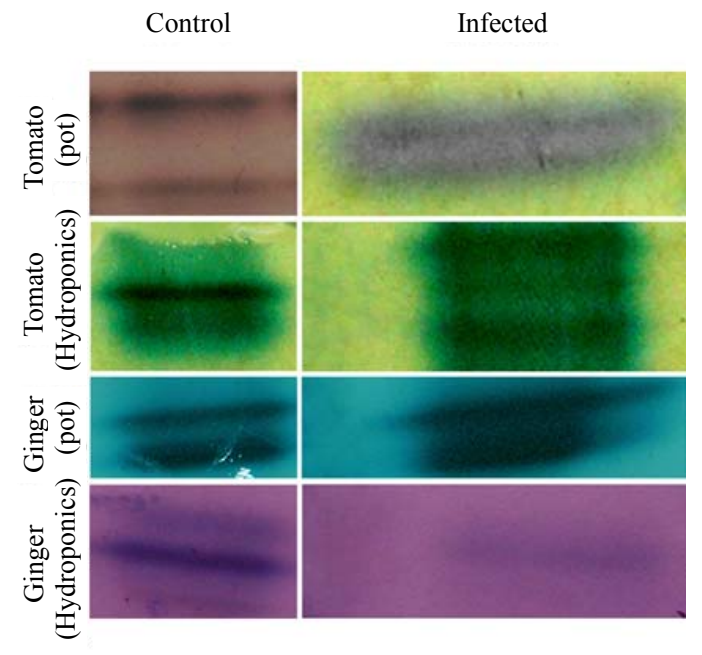

Figure 5. Isozyme profiles of POX of plants in pot and hydroponic systems with respective controls; left panel is the profiles of these five plants cultivated in pots, and right panel is of those cultivated as hydroponics. 
Table 2. Variations in superoxide dismutase isozyme bands: comparison of relative mobility values of all plants grown in

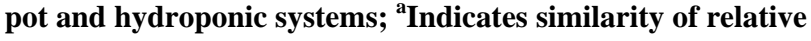
mobility between corresponding control and treated plants and ${ }^{b}$ Indicates similarity of relative mobility between treated plants in pot and hydroponic systems.

\begin{tabular}{|c|c|c|c|c|}
\hline \multirow{2}{*}{ Plant name } & \multicolumn{2}{|c|}{ Pot } & \multicolumn{2}{|c|}{ Hydroponics } \\
\hline & Normal & Treated & Normal & Treated \\
\hline \multirow{4}{*}{ L. esculentum } & 0.60 & $0.55^{\mathrm{b}}$ & $0.44^{\mathrm{a}}$ & $0.45^{\mathrm{a}}$ \\
\hline & 0.75 & 0.71 & 0.71 & $0.55^{\mathrm{b}}$ \\
\hline & 0.91 & 0.87 & 0.88 & 0.78 \\
\hline & & & & 0.94 \\
\hline \multirow{4}{*}{ Z. officinale } & $0.53^{\mathrm{a}}$ & $0.53^{\mathrm{a}}$ & 0.41 & 0.38 \\
\hline & 0.81 & 0.77 & 0.60 & 0.57 \\
\hline & 0.94 & 0.92 & 0.75 & 0.70 \\
\hline & & & 0.90 & 0.84 \\
\hline
\end{tabular}

Table 3. Variations in peroxidise isozyme bands: comparison of relative mobility values of all plants grown in pot and

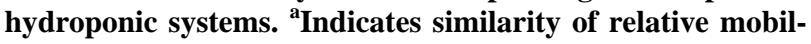
ity between corresponding control and infected plants.

\begin{tabular}{ccccc}
\hline \multirow{2}{*}{ Plant name } & \multicolumn{2}{c}{ Pot } & \multicolumn{2}{c}{ Hydroponics } \\
\cline { 2 - 5 } & Control & Treated & Control & Treated \\
\hline \multirow{2}{*}{ L. esculentum } & 0.49 & 0.17 & 0.26 & 0.18 \\
& 0.75 & 0.26 & $\mathbf{0 . 3 8}^{\mathrm{a}}$ & $\mathbf{0 . 3 8}^{\mathrm{a}}$ \\
& & & & 0.54 \\
Z. officinale & 0.30 & 0.23 & $\mathbf{0 . 3 6}^{\mathrm{a}}$ & $\mathbf{0 . 3 6}^{\mathrm{a}}$ \\
& 0.57 & 0.42 & 0.78 & 0.67 \\
\hline
\end{tabular}

\subsubsection{SOD Characterization}

SOD isozyme profile also showed variations (Figure 4 and Table 2). Both control and infected tomato in pot showed three isoforms each, while its hydroponic control showed three isoforms and corresponding infected had four isoforms with one isoform ( $\mathrm{Rm} \mathrm{0.44)}$ almost com mon. Both control and infected gingers in pot and as hydroponics showed three isoforms each with common $\mathrm{Rm}$ (0.53), while both control and infected hydroponics showed four isoforms each. In general, number of SOD isozymes in infected tomato and ginger was three with comparable $\mathrm{Rm}$ values, while infected mangroves showed 1 or 2 more isozymes than their respective controls.

\subsubsection{POX Characterization}

POX isozyme profile also showed variations (Figure 5 and Table 3). Both control and infected tomato in pot showed two isoforms each, while its hydroponic control showed two isoforms and corresponding infected had three isoforms with one Rm (0.38) in common. Both control and infected pot and hydroponic gingers showed 2 isoforms each with one $\mathrm{Rm}(0.36)$ in common for hydroponics. The results show that plants gown under hydropoic system expressed 1 or 2 more POX isozymes than their respective controls, however the number of POX isozymes was generally 2 in all tomato and ginger plants.

\subsubsection{CAT Characterization}

Unfortunately, catalase isoforms could not be visualised on the gel, but gas bubbles were liberated upon the addition of $\mathrm{H}_{2} \mathrm{O}_{2}$ to the staining solution, which clearly indicates the presence of catalase in the sample.

\subsection{Reconfirmation}

The Rs isolate used to induce biotic stress as described above was need to be reconfirmed that its virulence was not lost upon storage. Thus, it was injected in to a healthy ginger to confirm its virulence to cause wilt as in the parent plant from which the infected rhizomes were collected for isolating the Rs used in this study. Figure 6 demonstrates that Rs caused wilt in healthy ginger.

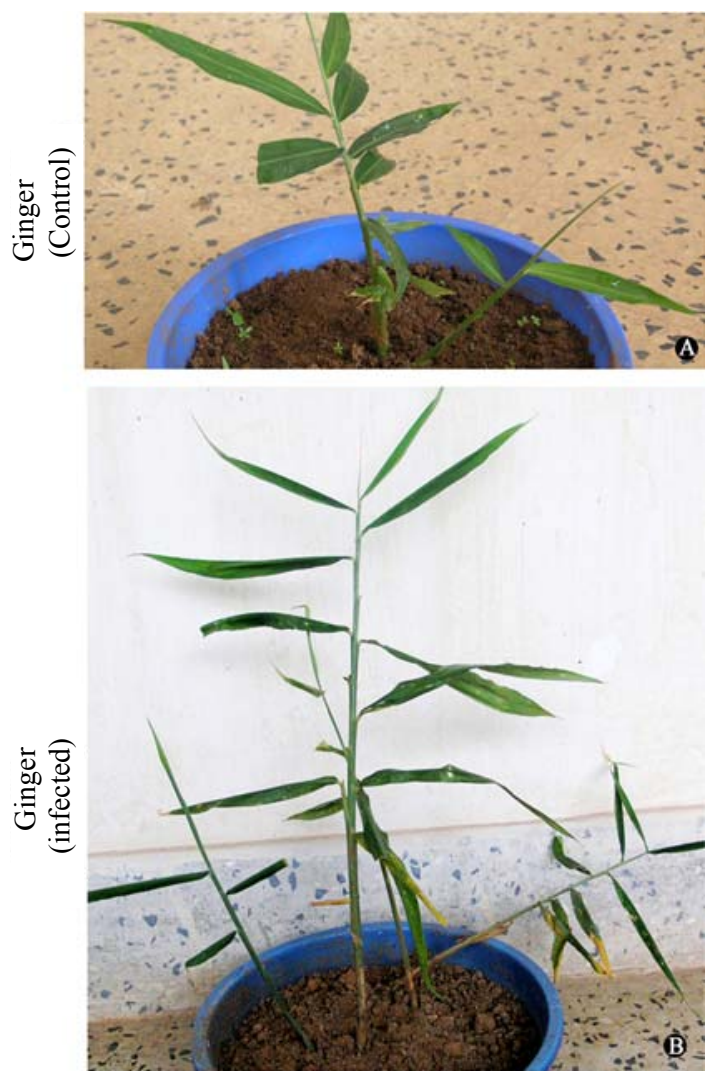

Figure 6. (a), (b) Reconfirmation of Rs virulence. (a) healthy ginger plant in pot, and (b) wilted ginger after three weeks of injecting the Rs isolate. 


\section{Discussion}

This study includes isolation and characterisation of $R$. solanacearum (Rs) from severely wilted ginger, transfer of Rs-induced biotic stress to selected plants and analyses of biochemical changes coupled with the isoenzymes profiles of oxidative stress enzymes (OSE). These test plants were grown under two conditions; viz., under normal (in pots) and controlled (hydroponics) systems to judge maximum possible differences upon induction of biotic stress. Rs induced biotic stress caused wilt symptom in ginger but did not cause any wilt symptom in tomato, even then the normal biochemical and OSE isozymes patterns of all plants, especially those grown as hydroponics were elicited to significantly higher levels.

The typical morphological evidences of wilting caused by Rs strains include rolling of the leaf margins, sectorial yellowing and necrosis, chlorosis and the stems may show brown to black discolouration - both externally and internally [18]. Three mechanisms have been proposed to explain the wilting disease: mechanical plugging of xylem vessels; toxic action of exopolysaccharides (EPS) secreted by the pathogen; and enzymatic attack on plant tissue [19].

We demonstrated pink and fluidal colonies of Rs in TZC and CPG agars, respectively with its typical biochemical characteristics coupled with arginate utilization in appropriate reactions and streaming thread formation form the wounds of infected plant. Such characteristics are typical of Rs. For a quick field diagnostic identification of Rs and to distinguish bacterial wilt from wilts caused by fungal pathogens, bacterial streaming from infected plant material can be used [4]. Milky white strand containing bacteria and EPS will stream from the cut ends of the xylem. On the basis of unique biochemical characteristics, Sambasivam and Girija [20] showed that fifteen isolates of Rs collected from ginger growing tracts of Palakkad, Ernakulam and Wynad Districts of Kerala (neighbouring districts of Kozhikode from where we isolated the Rs variant and conducted the experiments) and described them as biovar III A. They showed that all the isolates were appeared as small creamy white colonies with pink centre on TZC agar, and were positive to $\mathrm{KOH}$ solubility, nitrate reduction, production of catalase and oxidase, formation of ammonia from arginine, fermentation of glucose, oxidation of lactose, maltose, cellobiose, manitol and sorbitol. We also demonstrated similar characteristics of Rs isolate, and its retention of virulence even after many passages (storage and subcultures). Thus, the culture we described also expected to be Rs biovar III A.

Normal growth and development of plants is greatly dependent on the capacity to overcome various stressors (stress factors), which include biotic stress. A common indicator in all these adverse conditions is the production of reactive oxygen species (ROS) within different cellular compartments of the plant cell [21] and expression of stress enzymes like POX, SOD and CAT in response to these ROS.

We analysed the biochemical and molecular changes due to induced biotic stress, in two cultivars well known for susceptible to Rs attack in nature ginger and tomato. Our isolate caused wilt in ginger but contrary to our expectations it did not cause any wilt symptoms in tomato. However, the biotic stress could alter the biochemical and OSE profiles specially proline and phenol in both the cultivars and their production showed tremendous increase upon infection. Proline and phenol are considered as stress markers in plants which get induced during unfavourable condition [22]. Just before or concomitant with the appearance of a hypersensitive response was the increased synthesis of several members of pathogenicrelated proteins in the inoculated plants [23]. A variety of signaling molecules like ethylene and jasmonic acid were produced as both local and systematic disease resistance, which in turn activated various defence responses and resistance to certain pathogens [23]. In accordance with this, in our study, resistant cultivar tomato showed increased protein content while in ginger there was decrease in protein content after infection which indicated the lack of various signalling molecules to resist the bacterial infection.

Emerging evidences suggest that hormone signaling pathways regulated by abscisic acid, salicylic acid, jasmonic acid and ethylene, as well as ROS signaling pathways, play key roles in the crosstalk between biotic and abiotic stress signalling [24]. Our study mainly focussed on the effect of biotic stress responses on the biochemical and molecular patterns of the test plants. Even though ginger in both pot and hydroponics systems showed considerable increase in the production of stress markers like proline and phenolics other biomolecules like total carbohydrate, protein, reducing sugar and starch content did not show any significant change which may be the reason for their susceptibility. Tomato showed changes in the biochemical and isozyme patterns which helped them to tolerate the infection.

\section{Conclusion}

To our knowledge, this is the first ever study demonstrating the biotic stress induced changes in the pattern of biochemical components and the expression pattern of the OSE at isozyme levels. Our study, in general, showed that tomato cultivated in pot and as hydroponics produced elevated levels of total carbohydrate, starch, reducing sugars protein, phenolics and proline with minor exceptions to ginger. Unlike tomato, the Rs sensitive 
ginger showed decreased levels of starch and reducing sugars - a sign of low photosynthetic output - coupled with high contents of phenolics and proline, the popular stress markers. The stress induced hydroponics (which did not face any water stress and received sufficient balanced nourishments), generally produced more biochemical components (especially proteins, phenolics and proline) and more numbers of isozymes of OSE than the corresponding plants grown in pots. It indicates that they utilized their resources to resist the biotic stress through OSE, phenolics and proline. Further characterization of these metabolomes at molecular level would give an insight into the real picture of biotic stress induced crosstalk within the plant body, which would facilitate engineering of plants for resistance and thus shield them from pathogenic attack.

\section{Acknowledgements}

The research Grant No. 83/2007/ KSCSTE from the Kerala State Council for Science, Technology and Environment, Government of Kerala is gratefully acknowledged. The authors also declare that there exists no conflict of interest.

\section{REFERENCES}

[1] S. Genin and T. P. Denny, "Pathogenomics of the Ralstonia solanacearum Species Complex," Annual Review of Phytopathology, Vol. 50, No. 1, 2012, pp. 67-89. doi:10.1146/annurev-phyto-081211-173000

[2] M. Fegan and P. Prior, "Recent Developments in the Phylogeny and Classification of Ralstonia solanacearum," Presentation at the 1st International Tomato Symposium, Orlando, 2004.

[3] T. P. Denny, "Plant Pathogenic Ralstonia Species," In: S. S. Gnanamanickam, Ed., Plant Associated Bacteria, Part 3, Springer, 2006, pp. 573-644. doi:10.1007/978-1-4020-4538-7 16

[4] E. B. French, L. Gutarra, P. Alev and J. Elphinstone, "Culture Media for Ralstonia Solanacearum Isolation, Identification and Maintenance," Phytopathology, Vol. 30, No. 3, 1995, pp. 126-130.

[5] A. F. Wimer, S. L. Rideout and J. H. Freeman, "Temporal and Spatial Distribution of Tomato Bacterial Wilt on Virginia's Eastern Shore," Hort Technology, Vol. 21, No. 2, 2011, pp. 19.

[6] M. L. Paret, A. S. De Silva, R. A. Criley and A. M. Alvarez, "Ralstonia solanacearum Race 4: Risk Assessment for Edible Ginger and Floricultural Ginger Industries in Hawaii," Hort Technology, Vol. 18, No. 1, 2008, pp. 90-96.

[7] R. B. Smitha, T. Bennans, C. Mohankumar and S. Benjamin, "Oxidative Stress Enzymes in Ficus religiosa L.: Biochemical, Histochemical and Anatomical Evidences," Journal of Photochemistry and Photobiology, Vol. 95, No. 1, 2009, pp. 17-25. doi:10.1016/j.jphotobiol.2008.12.004

[8] R. Mittler, "Oxidative Stress, Antioxidants and Stress
Tolerance," Trends in Plant Science, Vol. 7, No. 9, 2002, pp. 405-410. doi:10.1016/S1360-1385(02)02312-9

[9] A. L. Carlos, and S. B. Leonardo, "Biovar-Specific and Broad-Spectrum Sources of Resistance to Bacterial Wilt (Ralstonia solanacearum) in Capsicum," Crop Breeding and Applied Biotechnology, Vol. 4, No. 3, 2004, pp. 350355.

[10] K. P. Asish, B. D. Anath and M. Prasanna, "Defense Potentials to $\mathrm{NaCl}$ in a Mangrove, Bruguiera parviflora: Differential Changes of Isoforms of Some Antioxidative Enzymes," Journal of Plant Physiology, Vol. 161, No. 5, 2004, pp. 531-542.

[11] H. D. Shew and G. B. Lucas, "Compendium of Tobacco Diseases," American Phytopathological Society, St. Paul, 1991.

[12] A. Kelman, "The Relationship of Pathogenicity of Pseudomonas solanacearum to Colony Appearance in a Tetrazolium Medium," Phytopathology, Vol. 44, No. 12, 1954, pp. 693-695.

[13] J. W. Shive and W. R. Robbins, "Methods of Growing Plants in Solution and Sand Cultures," Vol. 636, New Jersey Agricultural Experiment Station, 1937.

[14] S. Sadasivam and A. Manickam, "Biochemical Methods for Agricultural Sciences," Wiley Eastern Ltd., New Delhi, 1992.

[15] O. H. Lowry, N. J. Rosebrough, A. L. Farr and R. J. Randall, "Protein Measurement with the Folin Phenol Reagent," Journal of Biological Chemistry, Vol. 193, No. 1, 1951, pp. 265-275.

[16] U. K. Laemmli, "Cleavage of Structural Protein during the Assembly of the Head of Bacteriophage T4," Nature, Vol. 227, 1970, pp. 680-685. doi:10.1038/227680a0

[17] S. D. Ravindranath and I. Fridovich, "Isolation and Characterization of Manganese Containing SOD from Yeast," Journal of Biochemistry, Vol. 250, No. 15, 1975, pp. 6107-6112.

[18] J. G. Elphinstone, "The Current Bacterial Wilt Situa- tion: A Global Overview. Bacterial Wilt Disease and the Ralstonia solanacearum Species Complex," American Phytopathological Society (APS Press), St. Paul, 2005.

[19] H. Jahr, J. Dreier, D. Meletzus, R. Bahro and R. Eichenlaub, "The Endo- $\beta$-1, 4-glucanase CelA of Clavibacter michiganensis subsp. michiganensis is a Pathogenicity Determinant Required for Induction of Bacterial Wilt of Tomato," Molecular Plant and Microbe Interraction, Vol. 13, No. 7, 2000, pp. 703-714. doi:10.1094/MPMI.2000.13.7.703

[20] P. K. Sambasivam and D. Girija, "Biochemical Characterization of Ralstonia solanacearum Infecting Ginger," Annals of Plant Protection Sciences, Vol. 14, No. 2, 2006, pp. 419-423.

[21] M. N. Jithesh, S. R. Prashanth, K. R. Sivaprakash and A. K. Parida, "Antioxidative Response Mechanisms in Halophytes: Their Role in Stress Defence," Journal of Genetics, Vol. 85, No. 3, 2006, pp. 237-254. doi:10.1007/BF02935340

[22] W. Claussen, "Proline as a Measure of Stress in Tomato Plants," Plant Science, Vol. 168, No. 1, 2005, pp. 241-248. 
[23] L. C. Van Loon, "Pathogenesis-Related Proteins," Plant Molecular Biology, Vol. 4, No. 2, 1985, pp. 111-116.

[24] M. Fujita, Y. Fujita, Y. Noutoshi, Y, F. Takahashi, Y. Narusaka and K. Yamaguchi-Shinozaki, "Crosstalk be- tween Abiotic and Biotic Stress Responses: A Current View from the points of Convergence in the Stress Signaling Networks," Current Opinion in Plant Biology, Vol. 9, No. 4, 2006, pp. 436-442. 